UDC 614.1: 614.7

DOI: 10.21668/health.risk/2020.4.06.eng

Research article

\title{
METHODICAL ASPECTS IN ASSESSING RISKS OF COMORBID PATHOLOGY OCCURRENCE UNDER EXPOSURE TO CHEMICAL ENVIRONMENTAL FACTORS
}

\author{
O.A. Maklakova ${ }^{1,2}$, N.V. Zaitseva ${ }^{1}$, D.A. Kiryanov ${ }^{1,2}$ \\ ${ }^{1}$ Federal Scientific Center for Medical and Preventive Health Risk Management Technologies, \\ 82 Monastyrskaya Str., Perm, 614045, Russian Federation \\ ${ }^{2}$ Perm State University, 15 Bukireva Str., Perm, 614990, Russian Federation
}

Risk assessment methodology is a promising trend in examining effects produced by environmental factors on population health. However, at present little attention has been paid to issues related to comorbid pathologies occurrence under chronic exposure to toxicants.

Our research goal was to improve methodic approaches to assessing risks of co-morbid pathology occurrence under exposure to multi-component chemical factors in the environment.

Data and methods. To develop an algorithm for establishing a probability that comorbid pathology would occur, we analyzed scientific publications that focused on effects produced by technogenic chemicals on a body and health risk assessment methodology. Methodic approaches were tested with epidemiologic hygienic analysis techniques and statistical processing of data obtained via profound medical and biological examination of children living in Perm region where chemical enterprises were located.

Results. We suggested a systemic approach to assessing risks of co-morbid pathologies caused by complex exposure to chemical environmental factors; the approach includes reference groups creation; determining responses in critical organs and systems via stage-by-stage modeling within «chemical factor - exposure marker - marker parameter - disease» system; determining population and individual risks of environmentally induced comorbid diseases. The performed analysis allowed establishing marker parameters of bronchial asthma and comorbid pathologies occurrence in children living on a territory with multi-component contamination of ambient air predominantly with saturated spirits, aldehydes, and particulate matter. It was shown that a number of additional comorbid diseases that were probabilistically related to increased chemicals contents in the examined children's blood could amount up to $15 \%$, and a contribution made by the examined chemicals into comorbid pathology occurrence would reach 14.2-23.4\%.

Implementation of mathematical analysis procedures outlined in the present work will make for higher efficiency of activities aimed at managing and minimizing health risks for people living under combined exposure to chemical environmental factors.

Key words: chemical factors, risk assessment, exposure marker, biomarker of an effect, comorbid pathology, causeand-effect relations, medical and biological examinations.

Contemporary changes in the living environment and negative trends detected in morbidity among population in the Russian Federation require comprehensive research on factors that influence human health; it is especially vital for industrially developed regions [1-4]. According to data obtained via clinical and epidemiological examinations performed on territories where ecological situa- tion is rather adverse, prevalence of morbidity with respiratory diseases, diseases of the cardiovascular and nervous system, gastric and endocrine diseases is 1.2-2.6 times higher than on reference territories and functional deviations in critical organs or systems are 1.2-1.4 times more frequent. Poor quality of the environment was shown to be a leading factor in making life expectancy shorter [2, 4-10]. Not

(C) Maklakova O.A., Zaitseva N.V., Kiryanov D.A., 2020

Olga A. Maklakova - Doctor of Medical Sciences, Head of the Advisory and Polyclinic Department, Associate Professor at Department for Human Ecology and Life Safety (e-mail: olga_mcl@fcrisk.ru; tel.: +7 (342) 236-80-98; ORCID: http://orcid.org/0000-0001-9574-9353).

Nina V. Zaitseva - Academician of the Russian Academy of Sciences, Doctor of Medical Sciences, Professor, Scientific Director (e-mail: znv@fcrisk.ru; tel.: +7 (342) 237-25-34; ORCID: https://orcid.org/0000-0003-2356-1145).

Dmitrii A. Kiryanov - Candidate of Technical Sciences, Head of the Department of Mathematical Modeling of Systems and Processes; Associate Professor at Department for Human Ecology and Life Safety (e-mail: kda@fcrisk.ru; tel.: +7 (342) 237-18-04; ORCID: https://orcid.org/0000-0002-5406-4961). 
coincidentally, issues related to providing sanitary-epidemiologic welfare of population, raising life quality, and health protection are among key targets in the state social policy implemented in the country.

Health risk assessment is a significant component in prevention medicine. Establishing probability of undesirable effects related to impacts exerted by environmental factors underlies environmental quality management and population health preservation [11-19]. We should note that studies on assessing risks of negative effects on health primarily focus on specific diseases and don't always take into account complex impacts exerted by chemical factors $[4,6,17]$. Another problem is selecting relevant indicators for risk assessment. An interesting and promising aspect here is getting an insight into pathogenetic mechanisms that cause functional disorders in several organs or systems under exposure to a set of chemical environmental factors that might be rather long-term [8, 16, 20-23].

Recently, a lot of attention has been paid to assessing risks of comorbid pathology. It was shown that comorbid pathology was a multifactor phenomenon developing due to several factors such as hereditary predisposition, metabolic disorders, chronic infections, social causes, and environmental factors as well. When several diseases develop in a combination, it changes pathophysiological clinical course and clinical signs of each of them thus aggravating a patient's state; it can result in death at more mature age ${ }^{1}$ [24-28]. Over the last decades different scales have been suggested for detecting comorbid pathology predominantly among adult population; they are used in clinical practice for determining gravity of a disease and predicting unfavorable outcomes [25]. So far there have not been enough studies focusing on influence exerted by environmental factors on comorbid states development and assessing risks of comorbid pathology associated with impacts exerted by toxicants.
Our research goal was to develop methodical approaches to assessing risks of comorbid pathology development under multicomponent exposure to a set of chemical environmental factors.

Data and methods. To develop an algorithm for determining a probability that comorbid pathology might develop, we examined literature data on how technogenic chemicals influenced a human body and on methodology for assessing health risks under negative influences exerted by environmental factors. Methodical approaches were tested with epidemiologic and hygienic analysis procedures and statistical processing of data obtained via profound medical and biological examination of children living in Perm region where chemical enterprises manufacturing products with organic synthesis technologies were located. A reference territory was a territory where there were no industrial enterprises.

Results and discussion. In accordance with basic documents health risk assessment involved a systemic examination of all aspects in impacts exerted by an adverse factor on human health that included four stages; these stages allowed revealing probability of certain negative effects that might occur under exposure to a chemical detected in environmental objects.

Hazard identification stage involved determining a list of adverse chemicals that might produce effects resulting in health disorders among population and detecting critical organs and systems that were susceptible to negative effects produced by established risk factors taking exposure scenarios into account. Contamination sources were revealed and environmental objects quality was assessed as per data obtained via analyzing statistical reports (Form No. 2, TP-Air), results obtained via social and hygienic monitoring performed by Rosgidromet and Rospotrebnadzor's regional office, and data obtained via field observations that allowed assessing quality of the environment. It was

\footnotetext{
${ }^{1}$ Isaeva R.B. Peculiarities of comorbid chronic pathology in children in areas near the Aral sea where ecological situation is adverse: the thesis of the dissertation ... for the Doctor of Medical Sciences degree. Moscow, 2007, 48 p. (in Russian).
} 
established that over a 5-year observation period hygienic standards for ambient air quality were violated on the test territory as per contents of formaldehyde (13.3 average daily MPC), benzene (up to 7.7 average daily MPC), phenol (up to 3.5 average daily MPC), and particulate matter (up to 4.2 single maximum MPC). Besides, one third of samples contained methanol (up to 0.06 single maximum MPC).

The next stage, namely exposure assessment, involved calculating and analyzing risks of negative effects occurring under multi-component and multi-environment exposure to chemicals (hazard quotient and index) and it allowed identifying priority chemical factors that created unacceptable health risks for exposed population and establishing critical organs and systems that were damaged by them. Unacceptable risk levels were detected on the test territory for respiratory diseases (HI chronic is up to 13.3) associated with long-term exposure to particulate matter (HQ chronic is up to 9.6); pathology of the central nervous system (HI chronic is up to 6.4) and cardiovascular system (HI chronic is up to 5.1) caused by chronic exposure to benzene (HQ chronic is up to 4.25) and phenol (HQ chronic is up to 1.7); immune pathology (HI chronic is up to 7.6) caused by long-term exposure to benzene and formaldehyde (HQ chronic is up to 3.3).

We performed structural-dynamic analysis of morbidity and mortality among population basing on data obtained from official statistic reports (The Federal Statistic Observation report Form No. 12 «Data on a number of diseases registered among patients who live on a territory where a medical organization renders its services») and data on people applying for medical aid obtained from the Territorial Fund for Obligatory Medical Insurance. This analysis allowed us to reveal whether a health risk found its actual realization as a specific disease. Relative risk is a qualitative parameter showing a correlation between morbidity and influencing chemical risk factors. Dynamic analysis of statistical data obtained over the observation period on the test territory revealed that a growth in primary morbidity as per «Diseases of the respiratory organs» nosologic category among children amounted to $30.5 \%$, and primary morbidity with cardiovascular pathology increased by 6.4 times (up to $14.79 \%$ ). A number of children suffering from bronchial asthma and allergic rhinitis that were first diagnosed in them grew by 1.2-42.8 times. Performed epidemiologic analysis allowed establishing a cause-and-effect relation between impacts exerted by the examined chemical environmental factors and respiratory diseases $(\mathrm{OR}=1.97)$, gastric diseases $(\mathrm{OR}=1.7)$, and pathology of the nervous system $(\mathrm{OR}=3.6)$.

We performed a profound examination of reference groups in order to establish and quantitatively assess a probability of comorbid pathology among population living in residential areas exposed to a set of chemical factors. At an initial stage in the research we substantiated exposure markers via building non-linear logistic regression models ${ }^{2}$ taking into account obtained authentic correlations between concentration of a chemical on blood and inhalation exposure to it in ambient air:

$$
p=\frac{1}{1+e^{-\left(b_{0}+b_{1} a\right)}}
$$

where $p$ is a probability that contents of an examined chemical in blood deviate from the standard;

$a$ is a dose of a chemical introduced with ambient air, $\mathrm{mg} /(\mathrm{kg} \cdot$ day $)$;

$e$ is an exponent, an exponential function with its base being equal to an irrational number;

$b_{0}, b_{1}$ are parameters applied in a mathematical model.

We revealed that contents of benzene, phenol, formaldehyde, and methanol in examined children's blood had statistically significant cause-and-effect relations with doses of the said chemicals introduced with ambient air $\left(R^{2}=0.18-0.30 ; \quad 31.97 \leq F \leq 99.71\right.$; $p=0.0001-0,0005)$; subsequently, it allowed

\footnotetext{
${ }^{2}$ Chetyrkin E.M. Statistical forecasting methods. Moscow, Statistika Publ., 1977, 356 p. (in Russian).
} 
us to consider elevated concentrations of these chemicals to be exposure markers.

Medical and biological examination involves obligatory assessment of critical organs and systems susceptible to negative effects produced by established chemical risk factors. Diseases are diagnosed basing on results obtained via clinical-functional and laboratory research techniques. In case a correlation between a nosology and exposure to a chemical is revealed, one should only take into account those diagnoses that occur much more frequently than among non-exposed people $(p \leq 0.05)$ and correspond to functional disorders in damage organs or systems in a body.

When substantiating biomarkers of an effect, we took into account laboratory and functional parameters that reflected disorders in critical organs and systems and had significant deviations from physiological standards and from average parameters revealed in the reference group with frequency of occurrence exceeding $5 \%$. Subsequently, a correlation between a factor and a biomarker was established with a logistic model:

$$
p_{J}^{Z}=\frac{1}{1+e^{-\left(b_{0}+b_{1} X_{I}\right)}},
$$

where $p_{J}^{Z}$ is a probability that $j$-th biomarker will deviate from physiological standards under impacts exerted by $i$-th factor;

$e$ is an exponent, an exponential function with its base being equal to an irrational number;

$b_{0}, b_{1}$ are parameters applied in a mathematical model;

$x_{i}$ is a value of $i$-th chemical factor.

Besides, we determined a correlation between a biomarker and a disease that is given with the following formula:

$$
p_{J}^{Y}=\frac{1}{1+e^{-\left(b_{0}+b_{1} z_{I}\right)}}
$$

where $p_{J}^{Y}$ is a probability that $k$-th disease will occur depending on a value of $j$-th biomarker;

$e$ is an exponent, an exponential function with its base being equal to an irrational number; $b_{0}, b_{1}$ are parameters applied in a mathematical model;

$z_{j}$ is a value of $j$-th biomarker.

Under exposure to a set of factors a probability that $j$-th biomarker will deviate from the standard is given as:

$$
p_{j}^{Z}=1-\prod_{i}\left(1-p_{i j}^{Z}\right),
$$

where $p_{j}^{Z}$ is a probability that $j$-th biomarker will deviate from standard.

Complex influence exerted by biomarkers on a probability that $k$-th disease might occur was given as:

$$
p_{k}^{Y}=1-\prod_{j}\left(1-p_{j}^{Z} p_{j k}^{Y}\right),
$$

where $p_{k}^{Y}$ is a probability that $k$-th disease will occur.

Overall, when relationships are modeled sequentially within «exposure marker - laboratory / functional parameter of a response (biomarker) - disease» system, it allows revealing regularities in occurrence of diseases in respiratory organs and comorbid pathology (Figure).

Subsequently a probability $p^{Y}$ that comorbid pathology would occur was determined as per the following formula:

$$
p^{Y}=\prod_{k} p_{k}^{Y}
$$

At the final stage we used (4) and put (5) into (6) thus obtaining an overall formula for determining a probability that comorbid pathologies might occur:

$$
p^{Y}=\prod_{k}\left(1-\prod_{j}\left(1-\left(1-\prod_{i}\left(1-p_{i j}^{Z}\right)\right) p_{j k}^{Y}\right)\right) .
$$

Regression analysis involved testing the obtained models in order to determine their relevancy and authenticity; to do that, we applied one-factor dispersion analysis and took into account Fischer's test value with $95 \%$ significance, determination coefficient $\left(R^{2}\right)$ and Student's $t$-test for significance being $p \leq 0.05$. 


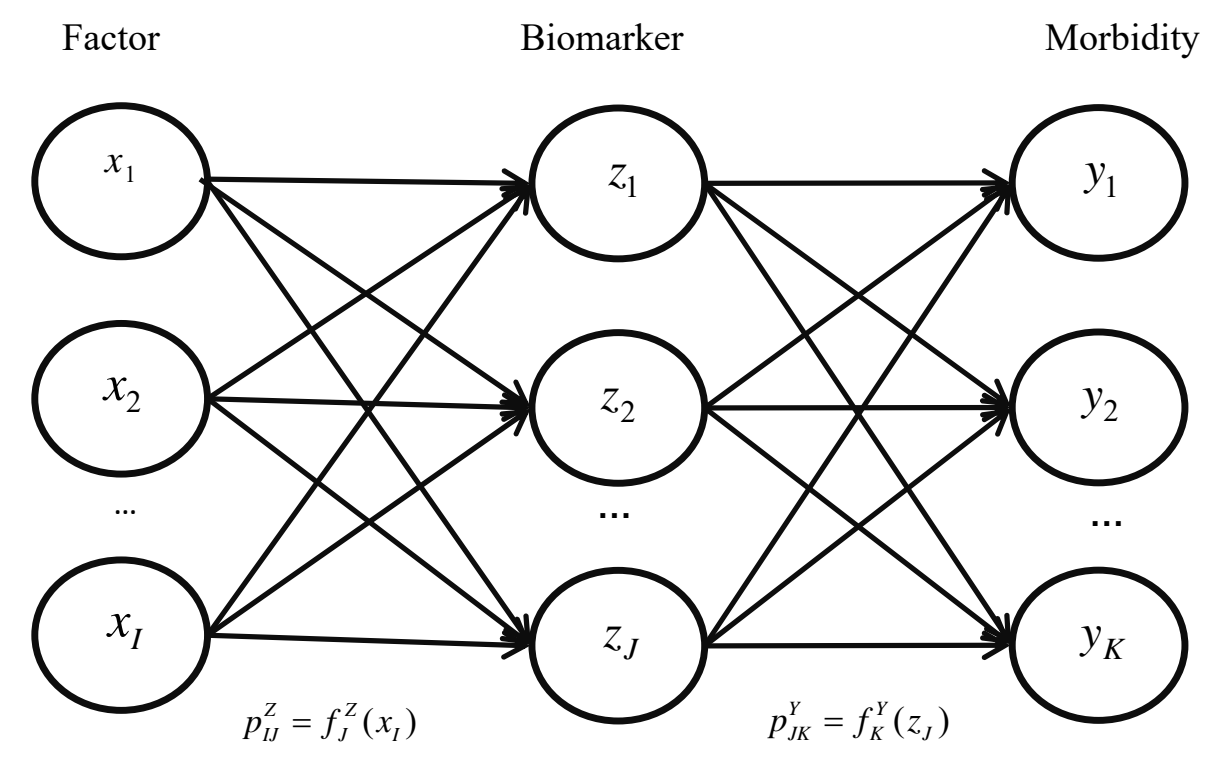

Figure. A graphic image showing results obtained via analyzing relations between comorbid pathology parameters

To establish biomarkers of an effect that were responses to increased concentrations of technogenic chemicals and that created pathogenetically justified relations, we comparatively analyzed internal relations within «exposure marker - laboratory / functional parameter of a response» system separately for exposed and non-exposed population.

Data obtained for the examined territory via performed sequential modeling allowed establishing biomarkers and cause-and-effect relations that characterized dependence between comorbid pathology development and deviations in markers under exposure to elevated concentrations of organic saturated alcohols, aldehydes, and particulate matter. We revealed several markers that predicted such negative effects as bronchial asthma $\left(\mathrm{P}^{\mathrm{y}}=0.13-0.29\right)$ and comorbid asthenoneurotic syndrome $\left(\mathrm{P}^{\mathrm{y}}=0.38-0.47\right)$ on the test territory where ambient air was contaminated with multi-component mixture of chemicals predominantly containing saturated alcohols, aldehydes, and particulate matter. Those markers included allergization index pathogenetically related to increased formaldehyde contents in blood $\left(R^{2}=0.52\right.$; $F=193.67 ; p=0.0001)$; increased contents of ionized calcium that was caused by increased phenol contents in blood $\left(R^{2}=0.52\right.$;
$F=193.67 ; p=0.0001$ ), creatine phosphokinase activity related to increased phenol and formaldehyde concentrations in blood $\left(R^{2}=0.59-0.69\right.$; $533.28 \leq F \leq 1,028.48 ; p=0.0001)$; activity of C-reactive protein related to increased benzene contents in blood $\left(R^{2}=0.42 ; F=233.0\right.$; $p=0.0001)$; lower superoxide dismutase activity caused by increased formaldehyde, benzene, and phenol contents in blood $\left(R^{2}=0.38-0.69\right.$; $188.63 \leq F \leq 287.67 ; p=0.0001)$ and average daily contents of particulate matter in ambient air $\left(R^{2}=0.53 ; F=291.03 ; p=0.0001\right)$; a decrease in lungs vital capacity detected via spirography and depending on elevated methanol concentration in blood $\left(R^{2}=0.41\right.$; $F=108.64 ; p=0.0001)$, and a decrease in maximum volume velocity at FEF25 caused by increased benzene and phenol contents in blood $\left(R^{2}=0.48-0.65 ; 324.95 \leq F \leq 613.16\right.$; $p=0.0001)$; increased average systolic blood pressure in the lung artery related to increased phenol concentration in blood $\left(R^{2}=0.83\right.$; $F=793.33 ; p=0.0001)$ and average daily contents of particulate matter in ambient air $\left(R^{2}=0.25 ; F=42.13 ; p=0.0001\right)$; and an increase in the range shown by heart rate study related to increased phenol concentration in blood $\left(R^{2}=0.58 ; F=485.6 ; p=0.0001\right)$. We established that additional cases of these comorbid pathologies that were probabilisti- 
cally related to increased methanol, formaldehyde, benzene, and phenol contents in blood and increased contents of particulate matter in ambient air could reach $14 \%$, and a contribution made by the examined chemicals into comorbid pathology development might be as high as $23.4 \%$.

So, markers predicting bronchial asthma $\left(\mathrm{P}^{\mathrm{y}}=0.13-0.29\right)$ and functional pathology in the gastrointestinal tract $\left(\mathrm{P}^{\mathrm{y}}=0.58-0.77\right)$ associated with aerogenic contamination with organic saturated alcohols, aldehydes, and particulate matter include elevated allergization index, ionized calcium contents, creatine phosphokinase and C-reactive protein activity, systolic blood pressure in the lung artery, the range in heart rate, lower superoxide dismutase activity, lower lung vital capacity and maximum volume velocity at FEF25. Apart from them, we should also mention an increase in total bilirubin contents related to elevated benzene, phenol, formaldehyde, and methanol concentrations in blood $\left(R^{2}=0.32-0.61\right.$; $58.93 \leq F \leq 517.70 ; p=0.0001)$. A number of additional bronchial asthma cases and comorbid functional pathology in the gastrointestinal tract that are probabilistically associated with increased methanol, formaldehyde, benzene, and phenol contents in blood and increased contents of particulate matter in ambient air can amount to $15 \%$, and a contribution made by the examined chemicals into comorbid pathology development might be as high as $14.2 \%$.

All the obtained data allow developing individual prevention programs based on established common pathogenetic mechanisms explaining how bronchial asthma and comorbid asthenoneurotic syndrome and functional pathology in the gastrointestinal tract develop simultaneously.

Conclusions. Suggested methodical approaches to assessing risks of comorbid pathologies occurrence under multi-component exposure to environmental factors have great practical value as they allow establishing correlation within «environment - population health» system, predicting population and individual risks of environmental diseases; all this is an obligatory component in giving evidence that damage was done to health during sanitary-epidemiologic investigations, inspections, and examinations.

When comorbid diseases formation under exposure to adverse multi-component chemical factors is examined with the suggested algorithm for risk assessment, it allows spotting out key components in pathogenesis of these diseases occurrence; it can give grounds for developing relevant medical and prevention programs.

Overall, use of suggested mathematical analysis procedures is aimed at making health risk management more efficient and minimizing health risks existing on territories where people live under combined exposure to various adverse chemicals that contaminate the environment.

Funding. The research was not granted any sponsor support.

Conflict of interests. The authors declare there is no any conflict of interests.

\section{References}

1. Klepikov O.V., Samoilov A.S., Ushakov I.B., Popov V.I., Kurolap S.A. Comprehensive assessment of the state of the environment of the industrial city. Gigiena i sanitariya, 2018, vol. 97, no. 8, pp. 686-692 (in Russian).

2. Leshchuk S.I., Surkova I.V., Senkevich N.V. Interrelation of environmental pollution and environmentally caused morbidity in the territory of technogenic pollution. Izvestiya vysshikh uchebnykh zavedenii. Severo-Kavkazkii region. Seriya «Estestvennye nauki», 2017, no. 2, pp. 110-117 (in Russian).

3. Movchan V.N., Zubkova P.S., Kalinina I.K., Kuznetsova M.A., Sheinerman N.A. Assessment and forecast of the ecological situation in St. Petersburg in terms of air pollution and public health indicators. Vestnik Sankt-Peterburgskogo universiteta. Nauki o Zemle, 2018, vol. 63, no. 2, pp. 178-193 (in Russian).

4. Meshkov N.A., Val'tseva E.A., Baeva Yu.I., Krylitsyna E.A. Assessment the conditionality of Samara city population incidence under the influence of environmental factors. Izvestiya Samarskogo nauchnogo tsentra Rossiiskoi akademii nauk, 2017, vol. 19, no. 2 (2), pp. 300-306 (in Russian). 
5. Pichuzhkina N.M., Chubirko M.I., Mikhal'kova E.V. Socially-hygienic aspects of environment-related diseases. Prikladnye informatsionnye aspekty meditsiny, 2018, vol. 21, no. 4, pp. 19-22 (in Russian).

6. Tabakaev M.V., Artamonova G.V. Particulate matter air pollution effects on the incidence of heart diseases among the urban population. Vestnik RAMN, 2014, no. 3-4, pp. 55-60 (in Russian).

7. Onishchenko G.G., Zaitseva N.V., Zemlyanova M.A. Gigienicheskaya indikatsiya posledstvii dlya zdorov'ya pri vneshnesredovoi ekspozitsii khimicheskikh elementov [Hygienic indication of consequences for health under environmental exposure to chemical factors]. Perm', Knizhnyi format Publ., 2011, 532 p. (in Russian)

8. Shevchuk L.M., Dzerzhinskaya N.A. Pecularities of dynamic health processes formation within a multicomponent air pollution. Profilakticheskaya i klinicheskaya meditsina, 2017, vol. 62, no. 1, pp. 25-28 (in Russian).

9. Preventing disease through healthy environments: a global assessment of the burden of disease from environmental risks. World Health Organization, 2016. Available at: http://www.who.int/iris/ handle/10665/204585 (02.09.2020).

10. West J.J., Cohen A., Dentener F., Brunekreef B., Zhu T., Armstrong B., Bell M.L., Brauer M. [et al.]. What we breathe impacts our health: improving understanding of the link between air pollution and health. Environ. Sci. Technol, 2016, vol. 17, no. 50 (10), pp. 4895-4904. DOI: 10.1021/acs.est.5b03827

11. Zavodova E.I., Os'kina O.F. Complex hygienic assessment of health and environmental factors. Sanitarnyi vrach, 2015, no. 4, pp. 43-46 (in Russian).

12. Kleyn S.V., Vekovshinina S.A., Sboev A.S. Priority risk factors of drinking water and the related with it economical loss. Gigiena i sanitariya, 2016, vol. 95, no. 1, pp. 10-14 (in Russian).

13. Kon'kova M.N., Spirin V.F. The levels of individual risks to the health of children depending on area of residence. Sanitarnyi vrach, 2018, no. 5, pp. 41-45 (in Russian).

14. Lomov O.P. Health and mortality risk as an assessment criteria of public health. Profilakticheskaya i klinicheskaya meditsina, 2018, vol. 67, no. 2, pp. 35-39 (in Russian).

15. Zaitseva N.V., Shur P.Z., May I.V., Kir'yanov D.A. On the question of the application of the prediction of the evolution of health risk in hygienic assessments. Gigiena i sanitariya, 2016, vol. 95, no. 1, pp. 106-112 (in Russian).

16. Zaitseva N.V., Zemlyanova M.A., Peregozhin A.N., Zhdanova-Zaplesvichko I.G. Scientific and methodological approaches to conducting the research for communication of health infringement with the multi-medical influence of chemical factors in the zone of influence of enterprises on production of aluminum and pulp and paper industry. Zdorov'e naseleniya i sreda obitaniya, 2017, vol. 294, no. 9, pp. 29-32 (in Russian).

17. Mezynska M., Brzóska M. Environmental exposure to cadmium - a risk for health of the general population in industrialized countries and preventive strategies. Environmental Science and Pollution Research, 2018, vol. 25, no. 4, pp. 3211-3232. DOI: 10.1007/s11356-017-0827-z

18. Peden D.B. The epidemiology and genetics of asthma risk associated with air pollution. Journal of Allergy and Clinical Immunology, 2005, vol. 115, no. 2, pp. 213-219. DOI: 10.1016/j.jaci.2004.12.003

19. Tajudin M.A.B.A., Khanb F., Mahiyuddin W.R.W., Hodd R., Latif M.T., Hamid A.H., Rahman S.A., Sahani M. Risk of concentrations of major air pollutants on the prevalence of cardiovascular and respiratory diseases in urbanized area of Kuala Lumpur, Malaysia. Ecotoxicology and Environmental Safety, 2019, vol. 171, pp. 290-300. DOI: 10.1016/j.ecoenv.2018.12.057

20. Zhang K., Batterman S. Air pollution and health risk due to vehicle traffic. Science of the Total Environment, 2013, vol. 15, pp. 307-316. DOI: 10.1016/j. scitotenv.2013.01.074

21. Bakirov A.B., Suleimanov R.A., Valeev T.K., Rakhmatullin N.R. Hygienic substantiation of risk factors to health of the population of territories with the developed oil refining. Bezopasnost' zdorov'ya cheloveka, 2016, no. 1, pp. 41-49 (in Russian).

22. Baktybaeva Z.B., Suleimanov R.A., Valeev T.K., Rakhmatullin N.R. Evaluation of oil refining and petrochemical industry impact on environmental and hygienic state of environmental objects and population health (literature review). Meditsina truda i ekologiya cheloveka, 2018, no. 4, pp. 12-26 (in Russian). 
23. McKenzie L.M., Crooks J., Peel J.L., Blair B.D., Brindley S., Allshouse W.B., Malin S., Adgate J.L. Relationships between indicators of cardiovascular disease and intensity of oil and natural gas activity in Northeastern Colorado. Environmental Research, 2019, vol. 170, pp. 56-64. DOI: 10.1016/j.envres.2018.12.004

24. Gudkov R.A., Konovalov O.E. Reasons and risk factors of the combined pathology in children. Rossiiskii mediko-biologicheskii vestnik im. akademika I.P. Pavlova, 2016, no. 2, pp. 144-152 (in Russian).

25. Zhuravlev Yu.I., Tkhorikova V.N. Sovremennye problemy izmereniya polimorbidnosti [Contemporary issues related to measuring polymorbidity]. Nauchnye vedomosti Belgorodskogo gosudarstvennogo universiteta. Seriya: Meditsina. Farmatsiya, 2013, vol. 154, no. 11, pp. 214-219 (in Russian).

26. Barnett K., Mercer S.W., Norbury M., Watt G., Wyke S., Guthrie B. Epidemiology of multimorbidity and implications for health care, research, and medical education: a cross-sectional study. Lancet, 2012, vol. 380, no. 9836, pp. 37-43. DOI: 10.1016/S0140-6736(12)60240-2

27. Menno di Bucchianico A.Di, Brighetti M.A., Cattani G., Costa C., Cusano M., De Gironimo V., Froio F., Gaddi R. [et al.]. Combined effects of air pollution and allergens in the city of Rome. Urban Forestry \& Urban Greening, 2019, vol. 379, pp. 13-23. DOI: 10.1016/j.ufug.2018.04.001

28. Tonelli M., Wiebe N., Guthrie B., James M.T., Quan H., Fortin M., Klarenbach S.W., Sargious P. [et al.]. Comorbidity as a driver of adverse outcomes in people with chronic kidney disease. Kidney International, 2015, vol. 88, no. 4, pp. 859-866. DOI: 10.1038/ki.2015.228

Maklakova O.A., Zaitseva N.V., Kiryanov D.A. Methodical aspects in assessing risks of comorbid pathology occurrence under exposure to chemical environmental factors. Health Risk Analysis, 2020, no. 4, pp. 55-62. DOI: 10.21668/health.risk/2020.4.06.eng

Received: 12.08 .2020

Accepted: 05.11.2020

Published: 30.12 .2020 